\title{
Diaphragm Ultrasography to Predict Respiratory Failure in Infants with Severe Bronchiolitis
}

\author{
Ana Gómez-Zamora ${ }^{1}$, Diego Rodriguez-Alvarez ${ }^{1}$, Iria Durán-Lorenzo ${ }^{2}$, Cristina \\ Schüffelmann ${ }^{1}$, Miguel Rodríguez Rubio ${ }^{3}$, and Paloma Dorao Martinez-Romillo ${ }^{1}$ \\ ${ }^{1}$ La Paz University Hospital Children Hospital \\ ${ }^{2}$ Great Ormond Street Hospital for Children \\ ${ }^{3}$ Hospital Universitario La Paz
}

April 7, 2021

\begin{abstract}
Objetive: To evaluate the ultrasonographic contractile activity indices of the diaphragm in infants with moderate and severe bronchiolitis supported with high-flow nasal cannula (HFNC) or non-invasive ventilation (NIV) to predict the need of invasive mechanical ventilation (IMV). Methods: Prospective observational study in infants admitted to a Pediatric Intensive Care Unit (PICU). Diaphragmatic excursion (dEx), diaphragmatic inspiratory (dTi) and expiratory time (dTe), and fraction of diaphragmatic thickening (dTF) were recorded at admission, $24 \mathrm{~h}$ and $48 \mathrm{~h}$ in both diaphragms. RESULTS: Twenty-six patiens were included ( 14 on HFNC and 12 on NIV) with a total of 56 ultrasonographic evaluations. Three patients required IMV. Sixty-four percent of the patients on HFNC required NIV as rescue therapy and 2/14 IMV (14,2\%). In the HFNC group there were no differences in dEx between those who required escalation to NIV or IMV and those who didn't. Diaphragmatic left thickening fraction (Left dTF) increased in patients on HFNC requiring IMV vs those needing NIV (Left dTF $47 \%$ vs $22 \%$ (1330); $\mathrm{p}=0,046, \mathrm{r}=0,7$ ) (Fig 2). Diaphragmatic inspiratory time was higher in infants on HFNC requiring IMV and diaphragmatic expiratory time was shorter ( $d L E T, p=0,038$; dRET, $p=0,022$ ). In the NIV group there were no diffenreces in dEx, dTi, dTe or dTF between patients needing escalation to IMV and those who didn't. We found no correlation between a clinical score and echographic dTF. CONCLUSION: In infants with moderate or severe brochiolitis receiving HFNC the use of ultrasonographic left dTF could help predict respiratory failure (RF) and need for IMV. The use of ultrasonographic diaphragmatic excursion is of little help to predict both.
\end{abstract}

\section{Hosted file}

Diaphragm Ultrasography to Predict Respiratory Failure in Infants with Severe Bronchiolitis v6.pdf available at https://authorea.com/users/406441/articles/517094-diaphragm-ultrasography-topredict-respiratory-failure-in-infants-with-severe-bronchiolitis

\section{Hosted file}

TABLES Diaphragm Ultrasonography to Predict Respiratory Failure in Infants with Severe Bronchiolitis.pd available at https://authorea.com/users/406441/articles/517094-diaphragm-ultrasography-topredict-respiratory-failure-in-infants-with-severe-bronchiolitis 

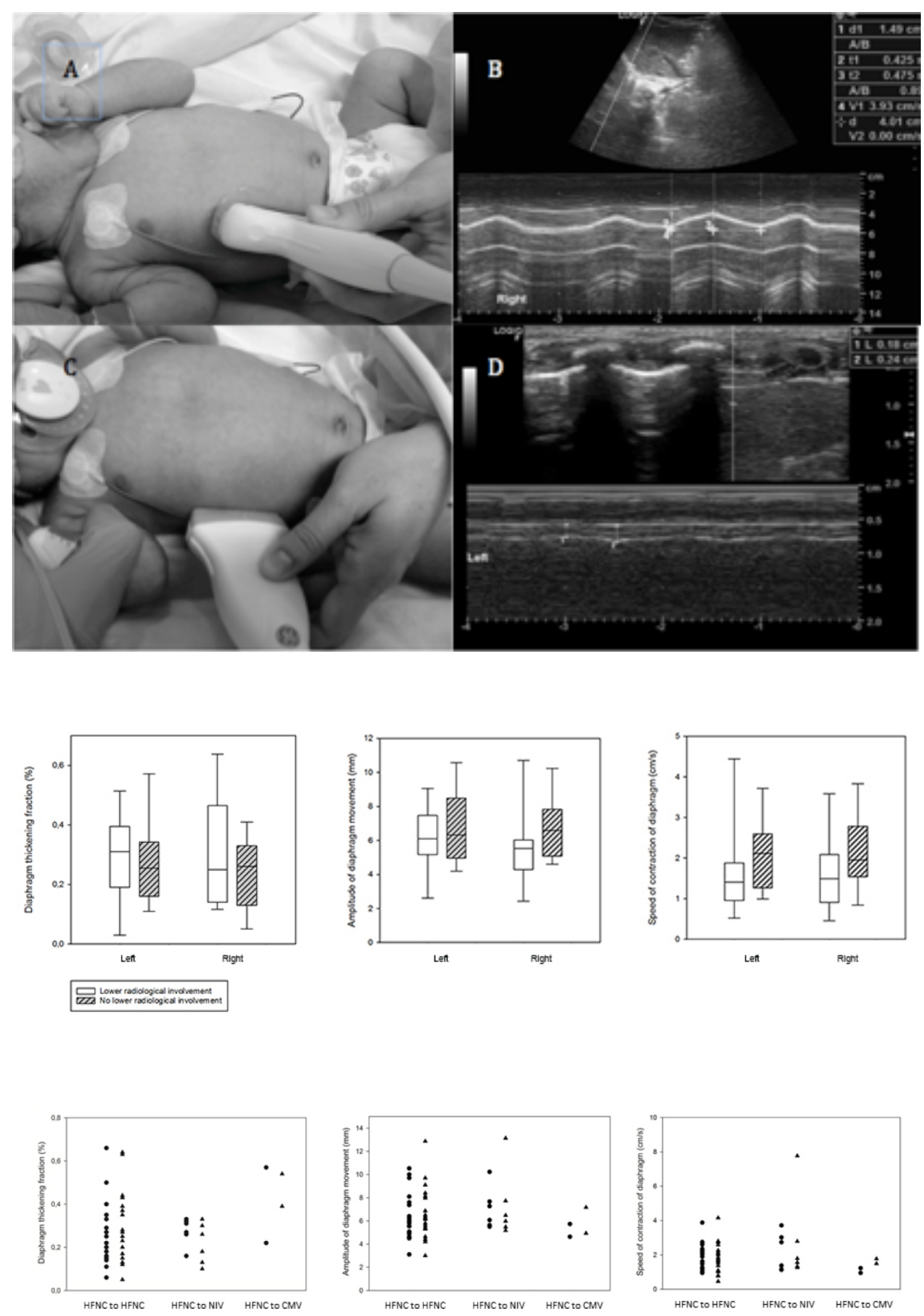

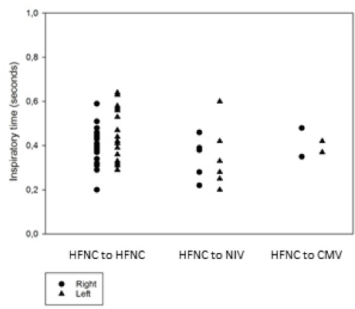
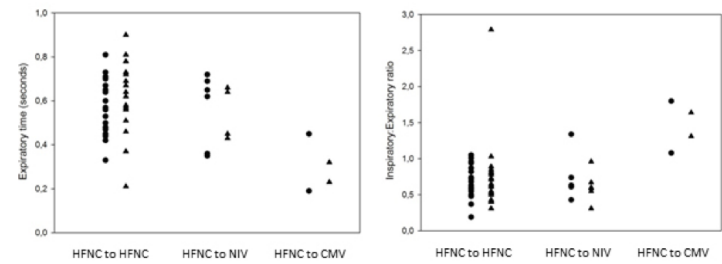